\title{
Investigation of Acid and Enzyme Wheat Straw Hydrolysis for Obtaining Polysaccharides
}

\author{
ZHAKSYLYK BAUMANULY MAKHATOV ${ }^{1 *}$, BAKHYTZHAN SHILMIRZAEVICH \\ KEDELBAYEV ${ }^{1}$, MADINA DZHAKASHYEVA ${ }^{1}$, AMINA DAULBAI ${ }^{1}$, BIBILGUL \\ ZAYDULLAYEVNA DOLTAYEVA ${ }^{2}$, USEN AKHANOV ${ }^{1}$, ROZA ABILDAYEVA ${ }^{1}$ \\ and ARAY KIRGIZBAYEVA ${ }^{3}$
}

'M.Auezov South Kazakhstan State University, Shymkent, Republic of Kazakhstan. ${ }^{2}$ South-Kazakhstan State Pharmaceutical Academy, Shymkent, Republic of Kazakhstan.

${ }^{3}$ Asfendiyarov Kazakh National Medical University, Almaty, Republic of Kazakhstan.

${ }^{*}$ Corresponding author E-mail: makhatov_8008@mail.ru

http://dx.doi.org/10.13005/ojc/350237

(Received: November 08, 2018; Accepted: March 06, 2019)

\section{ABSTRACT}

The processes of acid and enzymatic hydrolysis of wheat straw in the presence of the strain Aspergillus awamori F-RKM 0719 has been studied. Enzymatic hydrolysis is the most promising method of processing plant biomass. When carrying out the enzymatic hydrolysis of cellulosic materials, the yield of sugars reaches less than $20 \%$ of the theoretically possible yield. Overcoming the physico-chemical barriers that hamper the availability of cellulose for enzymes is an important issue, the solution of which is directly related to the search for low-cost pre-treatment methods for raw materials. The effectiveness of this process determines the yield of the target product in the process of enzymatic hydrolysis of cellulose and the economic feasibility of the entire technology as a whole.

Keywords: Wheat straw, Depolymerization, Polysaccharides, Enzymes, Enzymatic hydrolysis, Glucose

\section{INTRODUCTION}

Carbohydrates are the most common and widespread food component in nature $(70 \%$ of calories in a man's diet) ${ }^{1}$. Renewable plant biomass constitutes the bulk of organic material on Earth, and is an almost inexhaustible source of raw materials and energy ${ }^{2}$. Therefore, the development of effective ways of its using is one of the most urgent and priority tasks of modern biotechnology. Currently, the methods of using biomass are based largely on the enzymatic degradation of polysaccharide-making plant raw materials with the formation of oligo- and monosaccharides, which can then be converted by microbial or chemical synthesis into various widely sought products (alcohols, organic and amino acids, polymers, fodder additives, etc ${ }^{3-5}$.

This is an Open Access article licensed under a Creative Commons license: Attribution 4.0 International (CC- BY). Published by Oriental Scientific Publishing Company @ 2018 
Cellulose is the main polymer component of plant material and is the most common polysaccharide on Earth ${ }^{6}$. In nature, many microorganisms are known to produce a set of enzymes ${ }^{7}$ capable of destroying this insoluble polymer to soluble sugars, primarily cellobiose and glucose.

The areas of polysaccharide use are: medicine, food industry, microbiology, chemistry and agriculture.

Trends in the development of selection of producers of polysaccharides ${ }^{8}$ :

1) Search for producers among strains capable of utilizing cheap organic substrates (rather than traditional expensive sugars);

2) development of genetic approaches to obtaining producers.

3) An increase in the total activity of already known enzyme complexes (mainly by genetic engineering methods). At the same time, the solution of the problem of searching for the optimal qualitative and quantitative composition of the enzyme composition (enzyme preparation) for the most effective hydrolysis of polysaccharides of plant raw materials is of paramount importance.

Cellulose-containing raw materials (CCRM), agricultural waste and energy plant biomass are the most common renewable raw materials on the planet with an annual production of about 200 billion tons ${ }^{9}$. The main advantage of non-wood plant biomass (straw of agricultural plants) is its annual reproducibility and low cost.

Bioconversion of renewable plant material to fuel, fodder and food products, and intermediates for the chemical and microbiological industries is now considered as one of the key branches of biotechnology. The availability and cheapness of non-timber species made it possible to offer them as alternative sources for obtaining carbohydrates and biologically active substances ${ }^{10-13}$.

Bioconversion of renewable lignocellulosic biomass into biofuel and practically important products has been widely developed in different countries. Lignocellulosic raw materials (agricultural waste and wood) have great potential as cheap and renewable raw materials and consist mainly of cellulose, hemicellulose and lignin. Effective utilization of all three components plays an important role for competitiveness. For a more complete conversion of cellulose, it is necessary to increase its surface and destroy its microfibrillar structure, therefore, various pre-treatment methods (mechanical, physical, chemical, biological) play an important role in the bioavailability of cellulosecontaining raw materials ${ }^{14}$. Preliminary processing of CCRM is necessary to overcome the natural resistance of a matrix of three polymers (cellulose, hemicelluloses and lignin) to enzymatic hydrolysis. This stage determines the economic feasibility of the substrate preparation method and the efficiency of the enzymatic hydrolysis stage. Various methods for pretreatment of raw materials are known: processing of CCRM with dilute acids, thermobaric treatment without catalysts and with catalysts, alkaline delignification ${ }^{15,16}$. Hydrothermobaric treatment (GTBT) itself and additionally with pressure relief ("with explosion") as a method for obtaining cellulose-enriched raw material is the subject of modern research ${ }^{17-19}$.

The strength of the biomass lignocellulosic matrix under fermentation conditions is the main barrier to the economic realization of the production of glucose-pentose hydrolysates on an industrial scale. Therefore, the need to study individual factors that affect the enzymatic hydrolysis of pure celluloses is due to the desire to improve the process of enzymatic hydrolysis of various types of plant material ${ }^{10,11,12,13}$. Chemical inertness of plant polysaccharides (mainly cellulose) ensures the stability of the cell walls of plant cells and their protection from premature decomposition in nature, but complicates the process of biotechnological processing of plant raw materials. Therefore, the development and improvement of multi-enzyme systems designed for effective degradation of plant cell wall polysaccharides is one of the most urgent tasks of modern Biotechnology ${ }^{20}$.

Plant raw materials are the main source for the organization of biotechnological processes, the production of valuable food and feed products, which, when pretreated with acids or alkalis, enzymes, is a good substratum for microorganisms, can be used as nutrient media for industrial microbiology based on plant hydrolyzates ${ }^{21}$. It is known that lignocellulosic 
raw materials are only partially susceptible to enzymatic hydrolysis in its original form ${ }^{22}$. For efficient use of cellulose containing raw materials (CCRM) it is necessary to carry preprocessing in order to reduce the degree of cellulose crystallinity and increase the specific surface of the substrate. Various methods for pretreatment of CCRM are known, based both on physical-chemical, and on chemical and biological processes. The main factors affecting the efficiency of pre-treatment of plant raw materials are the type of biomass and acid, acid concentration, duration and reaction temperature ${ }^{23}$. When lignocellulose is treated with dilute acids, the porosity and total surface area increase. This is achieved by completely or partially removing hemicelluloses and / or lignin ${ }^{24}$.

Chemical hydrolysis - the reaction of formation of fermentable monosaccharides from cellulose and hemicelluloses - for a number of reasons gave way to enzymatic hydrolysis. To date, the enzymatic technology has become one of the most effective means of transformation of many types of biological materials ${ }^{25}$. The use of enzymes as biocatalysts allows to significantly expand the raw material base of the food industry and fodder production, increase the depth of processing of raw materials, create new types of food products and feeds, and improve the digestibility and organoleptic properties of the known ${ }^{26}$. In addition, the transition from traditional chemical to biotechnological methods in many cases is the only opportunity for the creation of waste technologies and environmentally friendly industries ${ }^{27}$. The use of plant biomass, as a renewable raw material rich in polysaccharides, determines the search for optimal methods for its processing. The main criterion for waste processing is their cost, volume, availability, chemical composition and technological properties. The processing of renewable plant materials in industrialimportant substances is of great practical interest. Cellulose-containing raw materials in Kazakhstan are available in practically unlimited quantities in the form of wood, straw, cotton plant waste (gouza-pai), solid household waste, etc. However, its effective conversion into biologically digestible sugars is a difficult task. The possibilities of using directly microorganisms, complexes of cellulolytic enzymes, chemical hydrolyzing agents for effective conversion of non-food raw materials into digestible sugars are being investigated ${ }^{28}$.

\section{MATERIALS AND METHODS}

The subjects of the study were: wheat straw, vegetable waste of cotton processing (guzapaya), wheat bran, cotton cellulose (cotton wool); Bioenzymes used were: Aspergillus awamori strain F-RKM 0719, Aspergillus terreus 461, Aspergillus terreus strain 499, Aspergillus oryzae.

The glucose concentration (cellulose hydrolysis product) was determined by the following methods: Dubois method, GO:PO (glucose oxidase:peroxide), dinitrosamysyl, Bertran method, iodine, resorcinol, Shomodi-Nelson method ${ }^{29,30}$. Analysis of reducing sugars was carried out by the method of McEn-Shorel.

Monosaccharide analysis of the hydrolysates was carried out using the high-performance liquid anion exchange chromatography method on a CarboPac PA-1 column (4 x 250 mm, Dionex, USA) using a PAD (Dionex) pulsed amperometric detector, as well as an Alliance chromatograph "Firm WATERS with a refractometric detector Waters 2414, on a column of Reprosil-Pur $\mathrm{NH}_{2}$ ( 4 × 250 mm," Dr. Maisch GmbH ", Germany).

Enzymatically active liquids of cellulolytic agents were used for the hydrolysis of cellulosecontaining substrates (wheat straw and bran, cotton cellulose).

Previously investigated plant raw materials were crushed and sorted. For chemical analyzes, raw materials were used, fractionated through a sieve with a particle size of 2-3 $\mathrm{mm}$.

The ash contents were determined by burning the sample of raw material, followed by calcination in a muffle furnace at a temperature of $600^{\circ} \mathrm{C}$; the content of readily and hardly hydrolysable polysaccharides was determined by the method of Kiesel and Semiganovsky, lignin by the König method in the Komarov modification using $72 \%$ sulfuric acid, pentosans by the content of pentoses in hydrolysates of easily and hardly hydrolysable polysaccharides ${ }^{31}$.

\section{Acid hydrolysis}

Wheat straw was subjected to autohydrolysis, after which the pulp was washed with water to obtain 
a solution of sugars. With aqueous extraction, up to $90 \%$ hemicelluloses passed into the solution. The next step involved the extraction of the degraded lignin. Lignin solvents were, by analogy with native lignin, dioxane-water (9:1), ethanol-water (9:1), they remove up to $90 \%$ lignin. In addition, a $\mathrm{NaOH}$ solution of 0.4 to $2 \%$ was used as the solvent. Thus, after a two-stage extraction, a product consisting mainly of cellulose was obtained. Such cellulose served as a starting material for the production of glucose. Cellulose treatment was carried out in the temperature range $190-250^{\circ} \mathrm{C}$ with a variation in the concentration of sulfuric acid from 0.6 to $2.5 \%$ by weight. The optimum temperature and duration of hydrolysis of cellulose with sulfuric acid were respectively $160^{\circ} \mathrm{C}-170^{\circ} \mathrm{C}$ and $30-80$ minute. As the concentration of sulfuric acid increased, the rate of decomposition of sugars increased also.

\section{Enzymatic hydrolysis}

The plant cell wall has a high resistance to degradation. Fungi and bacteria that use cellulose as a source of carbon have developed a complex set of enzymes that hydrolyse cellulose, releasing glucose monomers.

Experiments for the study of enzyme kinetics were carried out using wheat straw as a raw material. In the experimental processes of fermentolysis, preliminarily ground, sifted and dried to a constant value in a drying oven at a temperature of $120^{\circ} \mathrm{C}$ for $2 \mathrm{~h}$ wheat straw was used. The wheat straw was previously welded in an autoclave at an excess pressure of $0.05-0.1 \mathrm{MPa}$ for 0.5 - 1 hour.

The processes of fermentolysis were carried out in accordance with the characteristics of the enzyme preparations used while maintaining the active acidity in the $\mathrm{pH}$ range between 4.9-5 and temperature of $49^{\circ} \mathrm{C}$. The duration of fermentolysis was 7-10 hour.

\section{RESULTS AND DISCUSSION}

Based on the published literature data on the chemical composition (Table 1), taking into account the volume of annual waste generation ${ }^{32}$, we assume that wheat straw can be used as feedstock for depolymerization of polysaccharides.
Table 1: The chemical composition of wheat straw, in wt

\begin{tabular}{lc}
\hline Name of components & Content, \% \\
\hline Ash materials & 2,3 \\
Easily hydrolysable polysaccharides & 25,7 \\
Hardly hydrolysable polysaccharides & 41,3 \\
Gecosans & 35,3 \\
Pentozans (without uronic acids) & 24,5 \\
\hline
\end{tabular}

Among the methods of carrying out hydrolysis, the main ones are acid and enzymatic hydrolysis.

Despite the relatively high catalytic activity of sulfuric, hydrochloric and phosphoric acids, their use in the hydrolysis of lignocellulose is still not economically effective, since they have a strong corrosive activity, their cost is high, and the neutralization of their excess in hydrolysates is associated with costs and environmental stress. Using sulfuric acid is perspective, which allows to reduce the consumption of hydrolyzing agent due to its recovery ${ }^{33}$. In this regard, the determination of optimal pre-treatment regimes using sulfuric acid, as well as the study of the effect of its conditions on the efficiency of enzymatic hydrolysis of wheat straw is an urgent task The development of complex processing of wheat straw will not only improve the ecological situation, but also produce raw materials and additional products for the industry. The processing of straw was carried out in the temperature range of $190-250^{\circ} \mathrm{C}$ with a variation in the concentration of sulfuric acid from 0.6 to $2.5 \%$ by weight. The increase in temperature reduced the processing time required to achieve the maximum yield of reducing substances (RS) more than the decomposition reactions of polysaccharides. The yield of polysaccharides increased therefore with the reaction temperature. The influence of the concentration of sulfuric acid at temperatures below $150^{\circ} \mathrm{C}$ is markedly increased, but with increasing temperature to $160^{\circ} \mathrm{C}$ it disappears ${ }^{34}$.

The optimum temperature and duration of hydrolysis of straw with sulfuric acid were respectively $160^{\circ} \mathrm{C}-170^{\circ} \mathrm{C}$ and $30-80$ minute. As the concentration of sulfuric acid increased, the rate of decomposition of sugars increased. The optimum concentration of sulfuric acid was $1.77 \%$ by weight. Pretreatment of straw when the hydromodule was varied from 1: 3 to $1: 5$ was carried out under 
conditions of $1.6 \%$ by weight sulfuric acid and at a temperature of $150^{\circ} \mathrm{C}$. The highest yield of RS was achieved with the hydromodule 1:3, 5, 1:5 and $1: 5,8$ and amounted to $26.8 \%, 27.0 \%$ and $29.2 \%$ respectively. The polysaccharide composition of the hydrolysates was mainly represented by glucose, the concentration of which reached $25 \mathrm{~g} / \mathrm{l}$ in the hydrolysates.

Thus, the treatment of straw of $1.35 \%$ by weight with sulphurous acid at a temperature of $150^{\circ} \mathrm{C}$, a hydromodule of $1: 3$ for 60 min allows to obtain hydrolysates with a concentration of reducing substances up to $7.6 \%$, which will promote their further use in the microbiological industry. With the application of the hydromodule 1:4,5 the maximum concentration of reducing substances in the hydrolyzate was reached at a temperature of $160^{\circ} \mathrm{C}$, sulfuric acid concentration of $1.6 \%$ by weight. The yield of reducing substances was $25.57 \%$ of the absolutely dry substance. In all experiments on straw hydrolysis, the best results were achieved with a sulfuric acid concentration of $1.6 \%$ by weight and an experimental temperature of $150-160^{\circ} \mathrm{C} 35$. The results of the experiment are given in Table 2 .

Table 2: Results of fermentolysis of wheat straw in a fermenter

\begin{tabular}{lccc}
\hline $\begin{array}{l}\text { Process } \\
\text { number }\end{array}$ & $\begin{array}{c}\text { Number of enzymes, } \\
\text { units of activity }\end{array}$ & $\begin{array}{c}\text { The maximum } \\
\text { concentration of RS,\% }\end{array}$ & $\begin{array}{c}\text { Yield of } \\
\text { RS,\% }\end{array}$ \\
\hline 1 & $62-75,8$ & 0,43 & 4,3 \\
2 & $62-75,8$ & 0,46 & 4,6 \\
3 & $6,2-17,6$ & 0,46 & 4,6 \\
4 & $31-37,9$ & 0,48 & 4,8 \\
5 & $62-75,8$ & 0,32 & 3,2 \\
6 & $1,6-1,9$ & 0,26 & 2,6 \\
7 & $3,0-3,8$ & 0,26 & 2,6 \\
8 & $4,6-5,7$ & 0,22 & 2,2 \\
\hline
\end{tabular}

Model experiments for the study of enzyme kinetics were carried out using paper and cotton wool as the source of cellulose. In the experimental processes of fermentolysis, the wheat straw was preliminarily ground, sifted and dried to a constant value in a drying oven at a temperature of $120^{\circ} \mathrm{C}$ for 2 $\mathrm{h}$, which was previously welded in an autoclave at an excess pressure of 0.05-0.1 MPa for 0.5 - 1 hour.

The processes of fermentolysis were carried out while maintaining active acidity in the $\mathrm{pH}$ of 4.9-5 units of and temperature of $49^{\circ} \mathrm{C}$. The duration of the fermentolysis processes was 7-10 hour.
Studies of the kinetics and stoichiometry of the reactions of enzymatic hydrolysis of disperse solid-phase vegetable substrates were carried out by a vibatory fermentolizer with automated $\mathrm{pH}$ adjustment and thermostating ${ }^{36}$. The results of the experiment are given in Table 3.

Table 3. Results of fermentolysis of wheat straw in a fermenter

\begin{tabular}{cccc}
\hline $\begin{array}{l}\text { Process } \\
\text { number }\end{array}$ & $\begin{array}{c}\text { Number of enzymes, } \\
\text { units of activity }\end{array}$ & $\begin{array}{c}\text { The maximum } \\
\text { concentration of RS,\% }\end{array}$ & $\begin{array}{c}\text { Yield of } \\
\text { RS, \% }\end{array}$ \\
\hline 1 & $62-75,8$ & 0,43 & 4,3 \\
2 & $62-75,8$ & 0,46 & 4,6 \\
3 & $6,2-17,6$ & 0,46 & 4,6 \\
4 & $31-37,9$ & 0,48 & 4,8 \\
5 & $62-75,8$ & 0,32 & 3,2 \\
6 & $1,6-1,9$ & 0,26 & 2,6 \\
7 & $3,0-3,8$ & 0,26 & 2,6 \\
8 & $4,6-5,7$ & 0,22 & 2,2 \\
\hline
\end{tabular}

In order to reduce the error and verify the action of the enzyme on single-component substrates, a series of experiments was carried out on fermentolysis of crushed, buffered paper in fermentolysis with a volume of 6 liters. The results of comparative processes of fermentolysis of straw and paper are shown in Figure 1.

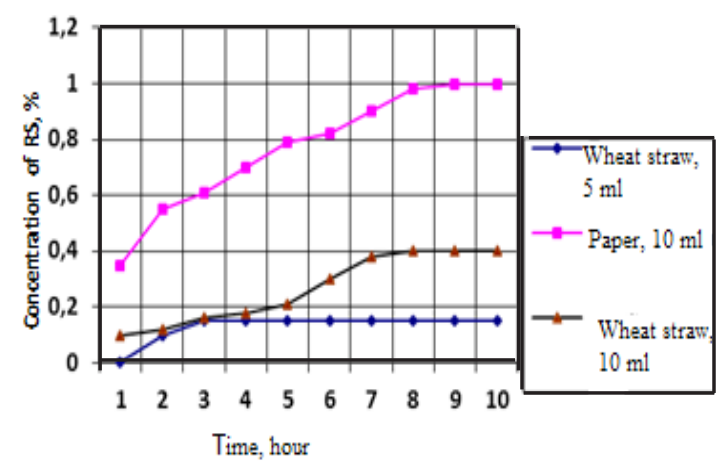

Fig. 1. Variation in the concentration of RS in the processes of fermentolysis of paper and wheat straw

Since the paper is practically pure cellulose, then, with the same kinetic parameters of the fermentolysis processes, the amount of formed sugars in the case of fermentolysis of straw would be 1.49 times less than when using paper. However, in reality, the structure of straw is characterized by a higher packing density of fibers and the presence of other interfering components, which leads to slowing down of the fermentolysis process 2.5 times $^{37}$. 


\section{CONCLUSION}

Analysis of the results of the conducted experiments allows to conclude that the most effective method of obtaining glucose from plant wastes is enzymatic hydrolysis. Enzymatic hydrolysis is promising from the point of view of creating independent low-waste technologies, gives the best yields of the target product $(90 \%)$, is carried out under mild conditions (low temperatures, atmospheric pressure). After cultivation of microorganisms, an experiment was performed comparing the efficiency of acidic and enzymatic hydrolysis in the production of hexoses (glucose) from wheat straw. The degree of conversion of plant raw materials to monosaccharides was determined at different time intervals after the onset of hydrolysis: after $3 \mathrm{~h}, 24$ h, 48 h, 72 hours.

The optimum temperature and duration of hydrolysis of wheat straw were respectively $160^{\circ} \mathrm{C}$ $-170^{\circ} \mathrm{C}$ and $30-80$ minutes. With an increase in the concentration of sulfuric acid, an increase in the rate of decomposition of sugars was observed, an optimum concentration of sulfuric acid was $1.6 \%$ by weight. Preprocessing of wheat straw with the variation of the hydromodule from $1: 3$ to $1: 5$ was carried out under conditions of $1.6 \%$ by weight of sulfuric acid and at a temperature of $150^{\circ} \mathrm{C}$. The highest yield of PB was achieved with the hydromodule 1:3, 5, 1: 5 and 1:5, 8 and amounted to $26.8 \%, 27.0 \%$ and $29.2 \%$ respectively.
Comparing the efficiency of hydrolysis 2 in different ways: acidic and enzymatic, we can conclude that the most effective strain for wheat straw is the Aspergillus awamori strain F-RKM 0719, but even this microorganism hydrolyses cellulose better than acids. The highest hydrolysis rate and the highest percentage of conversion of polysaccharides to monosaccharides are obtained as a result of enzymatic hydrolysis of wheat biomass, therefore, it is a promising raw material for obtaining polysaccharides and hence glucose and sorbitol. The parameters of this process have high values, namely the degree of conversion is $90.0 \%$.

Wheat straw can be used as a raw material for the enzymatic depolymerization of polysaccharides.

Optimum regimes of enzymatic hydrolysis of wheat straw (dosage of enzyme preparation $0.05 \mathrm{~g} / \mathrm{g}$ of substrate, temperature $50^{\circ} \mathrm{C}, \mathrm{pH} 5.0$, hydromodule 1:30) are established that allow obtaining a glucose yield of $63.97 \%$ of the content in the raw material, respectively.

\section{ACKNOWLEDGMENT}

This research did not receive any specific grant from funding agencies in the public, commercial, or not-for-profit sectors.

\section{REFERENCES}

1. Hoebler, C.; Barry, J. L.; David, A.; Delort-Lava, J. J. Agric. Food Chem., 1989, 37(2): 360-367.

2. Sanchez, O.J.; Cardona, C.A. Biores. Technol., 2008, 99, 5270-5295.

3. Ragauskas, A.J.; Williams, C.K.; Davison, B.H.; Britovsek, G.; Cairney, J.; Eckert, C.A.; Frederick, W.J; Hallett, J.P.; Leak, D.J.; Liotta, C.L.; Mielenz, J.R.; Murphy, R.; Templer, R.; Tschaplinski, T. The path forward for biofuels and biomaterials. Science., 2008, 311, 484-489.

4. Carmen, S. Biotechnol. Adv., 2009, 27, 185-194.

5. Menon, V.; Rao, M. Progr. Ener. Combustion Sci., 2012, 38, 522-550.

6. Bhat, M.K. Biotechnol., 2000, 18, 355-383.

7. Sun, Y.; Cheng, J. Bioresource Technnol., 2002, 83, 1-11.
8. Myriam, A.A.; Durán, T. S.; Aburto, J. Journal of Chemistry., 2017, 2017, 2-9.

9. Sadhu, S.; Maiti, T. K. British Microbiology Research Journal., 2013, 3(3), 235-258.

10. Sinitsyn, A.P.; Gusakov, A.V.; Chernoglazov, V.M. 1995, Moscow:, 224.

11. Silverstein, R.A.; Chen, Y.; Sharma-Shivappa, R. R.; Boyette, M.D.; Osborne, J. Bioresource Technology., 2007, 98, 3000-3011.

12. Yoshida, M.; Liu, Y.; Uchida, S.; Kawarada, K.; Ukagami, Y.; Ichinose, H.; Kaneko, S.; Fukuda, K. Bioscience, Biotechnology and Biochemistry., 2008, 72, 805-810.

13. Yu, Z.; Jameel, H.; Chang, H.M.; Philips, R.; Park, S. Biotechnology and Bioengineering., 2012, 5, 1449-1463. 
14. Lynd, L. R.;Weimer, P.J., van Zyl, W.H.; Pretorius, I. S. Microbiol. Mol. Biol., 2002, 66, 506.

15. Hu, F; Ragauskas, A. J. Bioenerg., 2012, 5, 1043-1066

16. Koegel, R.G.; Sreenath, H.K; Straub, R. J. Research Summaries., 1997, 25-27.

17. Zaldivar, J.; Nielsen, J.; Olsson, L. Appl. Microbiol. Biotechnol., 2001, 56, 17-34.

18. Jones, M.B.; Walsh, M. Published by Earthscan., 2001, 192, 506.

19. Hu, Z; Ragauskas, A. J. Ind. Eng. Chem. Res., 2011, 50, 4225-4230.

20. Bychkov, A.E.; Bukhtoyarov, V.A.; Eomovskii, O.I. Russian Chemical Bulletin., 2015, 64(5), 1189-1191.

21. Kuznetsova, B.N.; Danilova, V.G.;Yatsenkova, O.V.; Ibragimova, Ye.F.; Ivanchenko, N.M Journal of Siberian Federal University. Chemistry., 2009, 2, 156-164.

22. Labafzadeh, S. R. Academic dissertation. University of Helsinki. Finland.,2015, 74, 123.

23. Carvalho, M. L.; Sousa, R. Jr.; RodríguezZúñiga, U. F.; Suarez, C. A. G.; Rodrigues, D. S.; Giordano, R. C.; Giordano, R. L. C Brazilian Journal of Chemical Engineering., 2013, 30(03), 437 - 447.

24. Olsson, C. Thesis for the degree of doctor of philosophy. Chalmers University of technology. Gothenburg, Sweden., 2014, 63, .

25. Kadic, A. Doctoral Dissertation. Lund
University, Sweden., 2017, 73.

26. Andersen, N. Ph.D. Thesis. Technical University of Denmark., 2007, 153.

27. Palonen, H. Dissertation for the degree of Doctor of Technology. VTT Biotechnology. Helsinki. Finland., 2004, 80.

28. Makhatov, ZH.B.; Kudasova, D.Ye. Sbornik materialov IV mezhdunarodnoy nauchnoprakticheskoy konferentsii. Moskva., 2015, 115-118.

29. Somogyi, M. J. Biol. Chem., 1952, 195, 19-23.

30. Nelson, N. A. J. Biol. Chem., 1944, 153, 375-379.

31. Toda, M.; Takagaki, K.; Okamura, M.; Kondo, K. N.; Hayashi, K.; Domen, S.; Hara, M. Nature., 2005, 438. 178.

32. Palkovits, R.; Tajvidi, K.; Procelewska, R.; Rinaldi, R.; Ruppert, M. Green Chem., 2011, 12, 972 - 978.

33. Shimizu, K.; Furukawa, H.; Kobayashi, N.; Itaya, Y.; Satsuma, A. Green Chem., 2009, 1(11), 627-1632.

34. Yang, P.; Kobayashi, H.; Fukuoka, A. Chin. J. Catal., 2011, 32, 119-134.

35. Torpolov, M.A.; Tarabukin, D.V.; Frolova, S.V.; Shherbakova, T.P.; Volodin, V.V. Himija rastitel'nogo syr'ja., 2007, 3, 69-76.

36. Huber, G.W.; Iborra, S.; Conria, A. Chem. Rev., 2006, 106, 4044 - 4098.

37. Onda, A.; Ochi, T.; Yanagisawa, K. Green Chem., 2008, 10, 1033-1037 